\section{Box 1: HER-2 and Herceptin}

- What is HER-2 (human epidermal growth factor receptor 2)? Cell growth is controlled in part by growth factor receptors in cell walls. The HER-2 gene regulates the expression of HER-2 receptors. Patients considered to be HER-2 positive have HER-2 gene amplification. About $25 \%$ of patients with breast cancer have HER-2 gene amplification. These patients have an increased risk of metastases, shorter times to relapse and reduced overall survival.

\section{- What is Herceptin?}

Herceptin (trastuzumab) is a monoclonal antibody that inactivates HER-2 receptors, attracts killer cells and slows tumour growth.

\section{- Are there clinical trials of Herceptin?}

Currently, 27 ongoing clinical trials are listed at http://clinicaltrials.gov; several are recruiting patients in Canada. Most are for treatment of breast cancer (including Stage I, II and IIIA), but trials are also ongoing for trastuzumab therapy in colon cancer, sarcoma, osteosarcoma and endometrial cancer.

In an interim analysis of two unpublished trials involving women with Phase II and III breast cancers (phase-3 trials) the rate of disease recurrence over 4 years was $33 \%$ in women treated with chemotherapy alone and $15 \%$ in women treated with chemotherapy and trastuzumab. Adverse effects included cardiac dysfunction.

\section{- Ana Cartagena, University of Manitoba, Class of 2008}

more. What makes me anxious is the [media] coverage about trastuzumab, which makes it sound as if you're going to die if you don't get it right away."

The drug is also believed to be effective in women 6 months or more after completing chemotherapy, meaning that women who currently have or recently had breast cancer will now want to be tested for HER-2.

Although some provinces and oncologists routinely test for HER-2, many don't. This means that a rash of testing will be required to determine if these women are eligible. The test involves a biopsy of tumour tissue being sent to a pathology lab, a problematic prospect given the nation-wide shortage of pathologists. - Wayne Kondro, Ottawa and Barbara Sibbald, CMAJ

\title{
BMA House caught in the blast
}

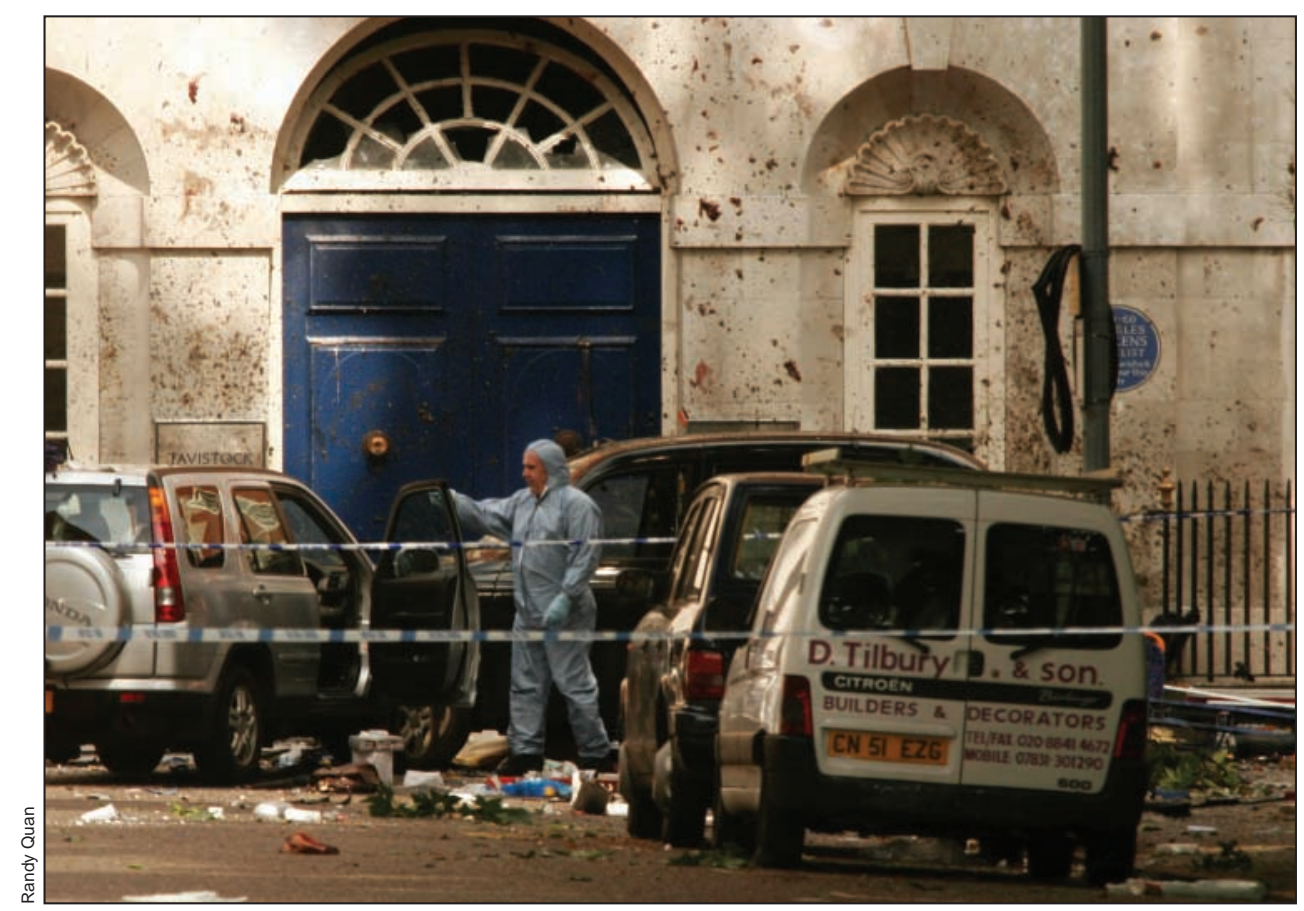

BMA House staff were first-hand witnesses and helpers in the July 7 London bombings. The bomb that destroyed the number 30 bus in Tavistock Square exploded directly outside BMA House, killing 13 and spreading "blood and flesh on the walls of BMA House," wrote Kieran Walsh (BMJ 2005;331:127). Physicians in the building helped the wounded before ambulances arrived. $B M J$ editor Fiona Godlee commended staff on their efforts to produce the journal without interruption from a contingency site as the "best answer to those who would tear our world apart" (BMJ 2005;331:0-g). — Sally Murray, CMAJ 